\title{
A Proposed Business Model for Customized Shared Farms in the Chinese Market Based on a National Undergraduate: Innovation and Entrepreneurship Program
}

\author{
Guo Guihang ${ }^{1}$, Wang Jingyuan ${ }^{1}$, Xie Weizhen ${ }^{1}$, Deng Zhishan ${ }^{1}$, Chen Zihuang ${ }^{1}$, Yu Xiaohui ${ }^{1}$, \& Cai Jindie ${ }^{1}$ \\ ${ }^{1}$ Guangdong University of Foreign Studies, China \\ Correspondence: Guo Guihang, School of English for International Business, Guangdong University of Foreign \\ Studies, No.2 Baiyundadaobei, Guangzhou 510420, P.R.China.
}

Received: February 18, 2021

Accepted: March 9, 2021

Online Published: March 16, 2021

doi:10.5539/ibr.v14n4p17

URL: https://doi.org/10.5539/ibr.v14n4p17

\begin{abstract}
With the deepening of reform and opening-up, the economy of China has developed rapidly. In recent years, shared farms have been one of the popular forms for the Chinese government to help the rural areas to shake off poverty. However, despite of many achievements, the business model of traditional shared farms cannot satisfy the growing market demands. Based on the research conducted under a national undergraduate innovation and entrepreneurship program, this paper starts with an analysis of the advantages and disadvantages of traditional shared farms and then proposes a business model that provides customized products and services. The feasibility of the proposed business model is discussed by using the IDIC model and some suggestions are put forth for the optimization of the business model for customized shared farms.
\end{abstract}

Keywords: shared farm, personalized customization, services

\section{Introduction}

The key to China's rural revitalization strategy is to solve the "three rural" problems. The agricultural supply-side structural reform aims to alleviate structural problems including unbalanced supply and demand of agricultural products, short agricultural industrial chain, low quality of agricultural products and low agricultural productivity in China. The characteristics of traditional shared farms include the emphasis on products, a single industrial structure, a fragile industrial chain, and obvious regional features. This mode of operation makes the traditional shared farms hard to develop. Based on a national undergraduate innovation and entrepreneurship program, this paper discusses the feasibility and the possible profitability of the business model for shared farms providing personalized products and services, and gives optimization suggestions for the operation mode of the exiting shared farms. Hopefully, this research may contribute to the theoretical research in the field of shared farms and the proposed business model of may provide a useful reference for running shared farms.

\section{Literature Review}

Diao Zhibo (2018) defined the shared farm as the result of the upgrade of leisure agriculture and rural tourism, which is a full combination of farm production and leisure, social, and experience activities. Zhu Wentao (2018) studied the utilization of idle resources in rural areas. He believes that "shared farm" is a professional operating company that integrates idle farmland. After professional planning, it is transformed into a farm and unified management. Consumers can place orders online through the network platform, and subscribe to farms to become members. The specialized operating company provides it with a farmland management model that provides the entire process from planting to harvesting and professional services. Shared farms can solve the problem of idle farmland in rural areas. The value of shared farms also lies in driving the development of related rural economies. Yang Yulong (2018) believes that standardizing shared farms can transform idle farm houses into homestays; and then use "Internet+" to connect with urban leasing needs to revitalize "sleeping assets".

Scholars have made corresponding research on the operating model of shared farms. They concluded that the main profit models of existing shared farms in domestic and foreign markets are product sales, resource sharing, value extension and theme marketing. Zhang Xin et al. (2019) pointed out that there were four current development models of shared farms abroad, including farm-community cooperation model, sightseeing vacation model, fully open model, and comprehensive model. As for the domestic shared farm, Kang Xingtao 
(2019) concluded three types of shared farm operation models including simple sharing models such as agricultural product recognition, platform shared farm models based on the construction of a network credit system, and smart shared farm models based on Internet of Things, artificial intelligence and big data. Xi Liya, Pen Yan (2020) studied the digital development and design of shared farm platforms, and proposed the NFF (Nginx+Flask+FFmpeg) development design model. Based on this development and design system, the model of network and sharing is applied to the farm, becoming a new model of modern agricultural development.

Räisänen Jaana et al (2021) studied the trust problem of the sharing economy and found that the trust mechanism between users and the platform is not perfect. Thus, to better implement the sharing economy, they proposed to establish a better trust mechanism to maintain loyal customer relationships. Wei Yiting and Li Hua (2020) proposed that shared farms are a new form of the sharing economy and a manifestation of the sharing economy in the agricultural economy. Its essence is a shared agricultural production and consumption model that weakens "ownership" and strengthens "use rights." He pointed out that the shortcomings of shared farms are for rational planning and confusion of functions. The biggest misunderstanding lies in focusing on construction and neglecting operation. The profitable means can include selling agricultural products, revitalizing the limited resources in rural areas, that is, renting and sharing, plus platform operations, that is, setting up its own online platform. Wei Ruhong (2018) proposed that in the context of "Internet +", the agricultural value chain should be constructed from three aspects: developing shared logistics, improving the Internet financial system, and establishing a brand image.

It can be seen that domestic and foreign scholars' researches on shared farms mainly focus on the existing operating models and benefits, and there are few researches on personalized products and customization operating models. In this regard, this paper proposes a new shared farm business model with customized products and services based on a national undergraduate innovation and entrepreneurship program successfully completed by the authors. And the feasibility of this business model will be explored by applying the theoretical model of identifying, differentiating, interactive, and customizing (IDIC) proposed by Peppers and Rogers (2004).

\section{Theoretical Foundation}

After studying the existing shared farms models, we find that there is no research applying the strategy of customer relationship management. In order to confirm that the new shared farm business model proposed by us is feasible, this paper takes the customer relationship management theory and IDIC model as a guide to carry out the research. Nowadays, more and more companies have realized the importance of customer relationship management (CRM) to their business strategies. Wang Yonggui (2018) proposed that the research on customer relationship management has gone through three stages. The first stage, in the 1980s, focused on identifying and measuring customer satisfaction and seeking to maximize customer satisfaction. The second stage, in the early 1990s, emphasized the relationship between customer satisfaction and major customer behaviors. The third stage is from the 1990s to the present. It mainly focuses on the relationship among customer satisfaction, service quality and profit. In this stage, enterprises have begun to link the construction and maintenance of customer relationships with profits. Jun Sun (2019) believed that with the rise and development of CRM in China, the marketing model of Chinese enterprises is transforming from "product-centric" to "customer-centric".

The IDIC model is a typical marketing model proposed by Peppers and Rogers (2004). This model is often applied to identify and analyze the needs of different customers, meanwhile, solve the problem of customer relationship management through interaction. Its focus is to meet the personalized needs of customers. Figure 1 below illustrates the model. 


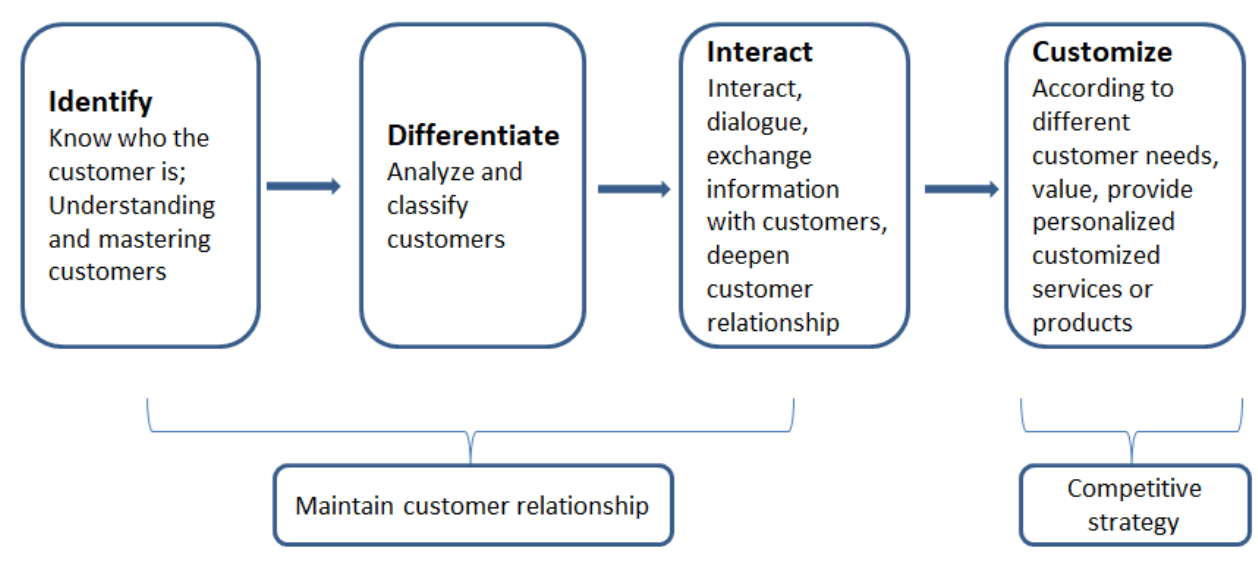

Figure 1. IDIC Model (Pepper and Rogers, 2004)

As illustrated by Figure 1, there are four steps in successfully implementing the IDIC model.

Step 1: Identify. Identifying customers is the first priority. That is to identify and to understand target customers based on resources and abilities of enterprises. This means that enterprises have to build a relationship with customers. The relationship should be established between the enterprise and a single customer rather than a group of customers. Enterprises should grasp customers' information as comprehensively as possible so that they can distinguish the customers with which they are in contact at any time, any place, and in any medium.

Step 2: Differentiate. According to the value of different customers brought to the company and the needs of different customers, enterprises could recognize the most valuable customers and the potential customers. Adopting a specialized strategy, enterprises provide different products and services to meet the needs of different customers, and concentrate resources to serve valuable customers. It requires the enterprise to establish its customer classification standards, and adjust the strategies according to the needs of important customers.

Step 3: Interact. Enterprises should keep interaction with customers to consolidate their relationships. Two key points consisting of understanding the customer needs and improving the efficiency of interaction. To enhance customer loyalty, enterprises can learn about customer needs and master their responses through each interaction, which could be used as the basis for the next step of the company. Each interaction and communication with customers should start from where they end last time, instead of repeating the information that has already been known.

Step 4: Customize. Different products or services are provided according to different customer needs and their value to the company. In order to maintain long-term customer relationships, enterprises may adjust their operation strategies to meet customer needs such as providing batch customized products or services. This part emphasizes the importance of one-to-one marketing. Marketers should make customers feel that the products or services they receive are suitable for them and different from others.

\section{Analysis of the Existing Business Model of Shared Farms}

The representatives of existing shared farms includes "Amy's Farm” in the United States, “MUJI みんなみ $の$ " and "Ma Farm" in Japan, "Guangdong Amy farm" and "Hainan Shared Farm" in China. Amy's Farm and MUJI み $ん$ みの のave similar business models, which mainly provide a platform for customers to experience farm life independently including farming, picking and raising animals. Compared with them, "Ma Farm" has its own characteristics that lease private farmland to customers but do not emphasize the uniqueness of products and services for different customers. As for the "Guangdong Amy Farm" in China, it is a representative of business models selling agricultural futures, with the single products and irregularly scheduled experiential farm activities as its two distinctive characteristics. However, as one of the latest shared farm, the operation modes of "Hainan Shared Farm" cannot excel any of the above mentioned.

In fact, the existing shared farms have already developed the business models recognized by the market for several years. These models can be summarized as follows: adoption of products, trusteeship, self-cultivation, and housing rental. For the existing shared farms, they pursue economies of scale that seems to be the key to increasing profits rather than personalization services. The operation strategies of providing personalized services have not been found in any of these shared farms. In other words, the existing shared farms have not yet 
realized the importance of customer relationship management and the application of the IDIC model in their business operation models.

From the perspective of customer relationship management (CRM), the demands vary from customer to customer. We need to adjust the farm operation strategies according to the customer demand in order to secure the customer loyalty, thus maintaining profitability and sustainable growth. Customer may tend to choose the farm that can better understand and satisfy their needs.

\section{Proposed New Business Model for Shared Farms Based on the IDIC Model}

\subsection{Analysis of Questionnaire Survey}

Before we propose a new business model that provides customized products and services and in order to verify this new model of personalized shared farm, we designed a questionnaire including 12 questions investigating from three aspects: satisfaction of current shared farms, pursuing personalized customization and favorites for personalized shared farms. The questionnaires were distributed to different groups of people and 454 valid samples were finally collected and analyzed.

\subsubsection{Descriptive Statistics}

Table 1. Statistical Characteristics of Respondents

\begin{tabular}{cccc}
\hline & Degree & Frequency & Effective percentage(100\%) \\
\hline \multirow{3}{*}{ Sex } & Male & 233 & 51.3 \\
& Female & 221 & 48.7 \\
& & 454 & 100 \\
& Under 18 & 9 & 2.0 \\
Age & $18-24$ & 16 & 3.5 \\
& $25-34$ & 95 & 20.9 \\
& $35-45$ & 229 & 50.4 \\
& Above 45 & 105 & 23.1 \\
\multirow{5}{*}{ Familiarity with shared } & 454 & 100 \\
farms & Very & 6 & 1.3 \\
& Unfamiliar & 17 & 3.7 \\
& Average & 83 & 18.3 \\
& Familiar & 232 & 51.1 \\
& Very familiar & 116 & 25.5 \\
\hline
\end{tabular}

As shown by Table 1, the age distribution of the respondents is concentrated, with half of the respondents aged between 34 and 45 . The respondents have a relatively high awareness of shared farms and $76.6 \%$ of them are familiar with shared farms.

\subsubsection{Reliability Analysis}

Table 2. Results of Reliability Analysis

\begin{tabular}{cccc}
\hline Dimension & Question & Cronbach's Alpha after deleting the item & $\begin{array}{c}\text { Cronbach's } \\
\text { Alpha }\end{array}$ \\
\hline Satisfaction of & 5 & .903 & .931 \\
current shared farms & 6 & .895 & \\
Pursuing & 7 & .903 & .979 \\
personalized & 8 & .968 & .974 \\
customization & 10 & .966 & .974 \\
Favorites for & 11 & .960 & .960 \\
personalized shared & 12 & .963 & \\
farms & 13 & 963 & \\
\hline
\end{tabular}

The Cronbach's Alpha coefficient is used to test the reliability within each dimension. The larger the Cronbach's Alpha coefficient is, the higher the reliability is. It is believed that the Cronbach's Alpha coefficient which is greater than 0.70 indicates that the scale is reliable.

The measured results are shown in Table 2. The $\alpha$ coefficient of satisfaction of current shared farms is 0.931 , the $\alpha$ coefficient of pursuing personalized customization is 0.979 , and the $\alpha$ coefficient of favorites for personalized shared farms is 0.974 . In other words, the $\alpha$ coefficient of the three measured dimensions is all above 0.70 , indicating high reliability and good internal consistency.

According to the data of " $\alpha$ coefficient after deleting the item" in the table, the " $\alpha$ coefficient after deleting this 
option" in each dimension is smaller than the $\alpha$ coefficient in the dimension, indicating that the reliability of the scale after deleting the item is reduced. Therefore, the existence of this item is conducive to improving the reliability of the scale, and the item should be retained.

\subsubsection{Dimensional Analysis}

Table 3. Dimensional Analysis of Pursuing Personalized Customization

\begin{tabular}{cccc}
\hline & Degree & Frequency & Effective percentage(100\%) \\
\hline Having ideas about & 1 & 1 & .2 \\
standard products & 2 & 7 & 1.5 \\
and services & 4 & 7 & 1.5 \\
& 5 & 347 & 76.4 \\
& 1 & 92 & 20.3 \\
Preferences for & 2 & 454 & 100 \\
personalized products and & 3 & 1 & .2 \\
services for relaxation & 4 & 7 & 1.5 \\
& 5 & 346 & 1.8 \\
& 1 & 92 & 20.3 \\
Preferences for the & 2 & 1 & 100 \\
autonomy in the course of & 3 & 754 & .2 \\
entertainment & 4 & 340 & 1.5 \\
& 5 & 98 & 1.8 \\
& & 454 & 21.9 \\
& & 7 & 100 \\
\hline
\end{tabular}

Table 3 shows the results of three specific questions. It is concluded that the majority of respondents have a tendency towards personalized shared farms. About $96.5 \%$ of respondents have strong ideas about the products and services of the shared farms. Most of them have preference to personalized products and pursue autonomy on shared farms.

\subsubsection{T-test}

Table 4. Independent Sample T-test

\begin{tabular}{ccccccc}
\hline Variable & Group & Sample & Mean & Standard deviation & t & Sig. \\
\hline Satisfaction & $\begin{array}{c}\text { Satisfaction } \\
\text { with } \\
\text { personalized } \\
\text { farms } \\
\text { Satisfaction } \\
\text { with current } \\
\text { farms }\end{array}$ & 454 & 4.153451 & .5186694 & & \\
& 454 & 1.933186 & .5028152 & 65.448 & .000 \\
\hline
\end{tabular}

Note: significance level is $5 \%$.

To discuss the market preference, the independent sample t-test was conducted on the satisfaction of different type of shared farms. The mean value of three questions in first dimension for each respondent represents the satisfaction with current farms, while the mean value of three questions in third dimension represents the satisfaction with personalized farms. The results showed that the mean value of satisfaction with personalized farms was 4.15 , the mean value of satisfaction with current farms is 1.93 , and significance is 0.000 . Therefore, there is a significant difference in the two groups towards satisfaction and the satisfaction with personalized farms is much higher than that of current farms.

\subsection{The Proposed New Business Model for Shared Farms}

The above analysis show that the personalized shared farm model has gradually become a trend in the market and is sufficiently attractive to customers who like shared farms. In view of this, we propose a new business model for the shared farms in China, which is illustrated by Figure 2. 


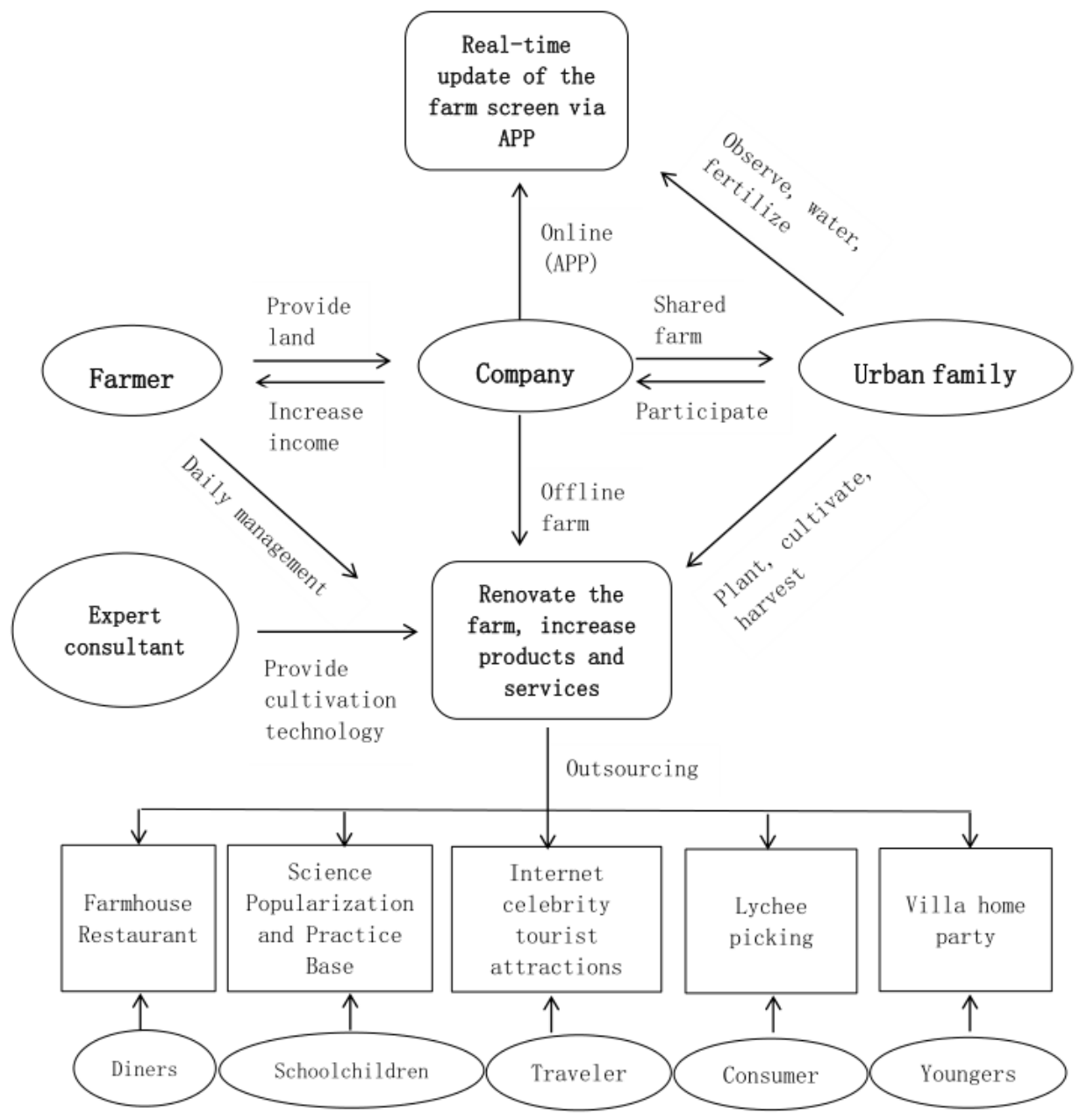

Figure 2. A Proposed New Business Model for Shared Farms

The above business model for shared farms has been simulated and approved to be feasible during our one-year research period of the national undergraduate innovation and entrepreneurship program funded by the Ministry of Education. This business model is built on the philosophy of IDIC and the detailed description of the features of this model is as follows:

Firstly, meeting the individual needs of customers. The operator of shared farms divides the farm area, and carries out planning, design and decoration. The farmland could be decorated as the customer wanted. In this regard, the new model of shared farms provides customers with personalized services. Compared with traditional shared farms, customers rent a place not only for planting but also for satisfying their different needs, such as family gathering. For customers who simply require for organic food, there is a professional team to provide specialized suggestions on it.

Secondly, offering full trusteeship model and semi-hosted model. Under the full trusteeship model, customers place an order for species and quantity of organic food on the official account. And products will be picked and packaged when mature and delivered to customers. Under the semi-hosted model, customers can experience the whole process of planting and harvesting. Whether it is a full trusteeship model or a semi-hosted model, products are decided by customers, the farm only provides guidance and help, and all services are adjusted according to different customer needs.

Thirdly, providing online real-time update services. Customers who demand growing organic vegetables on the leased land can look after their plants through apps, mini-programs, and official accounts. To be specific, the functions of the application include but are not limited to the following: a) Updating the farm and crop animation screens regularly. Customers can observe the status of the crops at any time at any place; b) Controlling remotely and issuing instructions including watering and fertilizing. The farmer on the farmland performs the 
corresponding operations according to the instructions; c) Reminding the plant of maturity. The customers can pick them by themselves or choose to hire people to harvest.

Fourthly, performing shared visits on leased farmland. Customers are authorized to freely arrange the farmland so that they can open it to visitors and charge them if they want. Based on the shared model, customers and farm operators work together to satisfy their benefits and achieve a win-win situation.

Finally, establishing other forms of sharing platforms. a) Establishing science popularization and practice bases for middle and high school students with functions including rare crop exhibitions, crop growth and so on; b) Creating fee-based photography attractions, namely, internet celebrity check-in points, which have become popular nowadays; c) Farm-style restaurant, which allows diners to enjoy the taste of nature; d) self-service picking activities, which is charged by weight of the products picked by customers.

\section{Conclusion}

Based on the one-year simulated operation of the above proposed new business model for shared farms under the national undergraduate innovation and entrepreneurship program funded by the Ministry of Education, we have verified the feasibility of this new business model. The contribution of this research is that, based on the IDIC model, we have set up a new operational mode for shared farms to meet the personalized needs of customers.

This research is of great significance to the related theoretical research and practical guidance of existing farm management. On the one hand, this new mode of research fills up the gaps in related theoretical research, and at the same time provides new ideas for other scholars to refer to; on the other hand, this new model removes the dissatisfaction of consumers who would like to share farms with the existing farms, and also provides a new direction for the next round of reforms for existing shared farms. In other words, nowadays, more and more enterprises in China have applied the IDIC model in their business strategy and it can be expected that the new business model of shared farms will become the mainstream of the shared farm industry in the near future.

\section{References}

Diao, Z. B. (2018). Analysis of the Construction Content and Mode of Shared Farms in Heilongiiang Province. Foreign Economics and Trade, 04, 36-38.

Don, P., \& Martha, R. (2004). Managing customer relationships. John Wiley \& Sons.

Kang, X. T. (2019). Study on the Operation Model of Shared Farms. Management Observation, 02, 111-112. https://doi.org/10.18261/issn.2535-6003-2019-02-01

Räisänen, J., Ojala, A., \& Tuovinen, T. (2021). Building Trust in the Sharing Economy: Current Approaches and Future Considerations. Journal of Cleaner Production. https://doi.org/10.1016/j.jclepro.2020.123724

Sun, J. (2019). Coal Marketing Course. Xuzhou: China University of Mining and Technology Press.

Wang, Y. G. (2018). Customer Relationship Management (essential edition). Beijing: Higher Education Press.

Wei, R. H., \& Fang, D. (2018). Research on the Construction Path of Agricultural Value Chain under the Background of "Internet +". Agricultural Economics, 7, 3-5.

Wei, Y. T., \& Li, H. (2020). Research on Shared Farms Based on the New Form of Urban and Rural Inclusion. Anhui Agricultural Science Bulletin, 26(22), 16-17+33.

Xi, L. Y., \& Pen, Y. (2020). Design and Application of A Development Framework Based-on Shared Farm Digital Control Platform. E3S Web of Conferences.

Yang, Y. L. (2018). It's Worth Trying to Revitalize Idle Farm Houses with Shared Farms. China Business Daily, May 2, p2.

Zhang, X., Xin, J. H., \& Zeng, X. L. (2019). The Impact of the Shared Farm Model at Home and Abroad on the Development of China's Agricultural Tourism. Farm Economic Management, 05, 5-9.

Zhu, W. T., Luan, J. D., \& Zhu, L. L. (2018). Research on the Utilization of Rural Idle Resources from the Perspective of Sharing Economy. Journal of Xichang College (Social Science Edition), 30(04), 52-57+71.

\section{Copyrights}

Copyright for this article is retained by the author(s), with first publication rights granted to the journal.

This is an open-access article distributed under the terms and conditions of the Creative Commons Attribution license (http://creativecommons.org/licenses/by/4.0/). 